\title{
Ensino e aprendizagem significativa
}

\author{
Ravi Cajú Duré \\ Universidade Federal da Paraíba (UFPB), João Pessoa/PB - Brasil \\ Maria José Dias Andrade \\ Universidade Federal da Paraíba (UFPB), João Pessoa/PB - Brasil
}

MOREIRA, M. A. Ensino e aprendizagem significativa. São Paulo: Editora Livraria da Física, 2017. 201 p.

O livro é a obra mais recente do físico e doutor em ensino de ciências Marco Antônio Moreira, um dos pesquisadores brasileiros de maior renome no que diz respeito à Teoria da Aprendizagem Significativa (TAS). Na referida obra, a TAS é abordada de maneira completa e exemplificada, abrangendo os significados originais propostos por David Ausubel e também pelas contribuições de David Bob Gowin e Joseph Novak. Como aspecto diferencial da abordagem feita em seus outros livros, Moreira relaciona a TAS à teoria dos campos conceituais de Gérard Vergnaud e à pedagogia da autonomia de Paulo Freire, incorporando também o seu enfoque crítico.

Os três primeiros capítulos apresentam uma análise crítica do ensino contemporâneo, em que são descritas as características das primeiras teorias behavioristas e sua influência na prática escolar contemporânea. Nesse contexto, a TAS é apontada como alternativa para um ensino centrado no aluno, estimulando o desenvolvimento de atividades colaborativas e o aprender a aprender criticamente. Os três últimos capítulos descrevem a TAS através da perspectiva de Ausubel, Novak e Gowin, relacionando-a com os campos conceituais de Vergnaud e com a pedagogia da autonomia de Freire e apresentando as contribuições dessas teorias para a prática de ensino. Por fim, o autor descreve a técnica dos mapas conceituais e os utiliza como estratégia facilitadora para a explicação das teorias abordadas no livro.

Os temas trabalhados na obra serão apresentados de forma contínua, compondo o seguinte percurso teórico: origem e influências do behaviorismo na escola contemporânea, aprendizagem significativa como uma resposta ao ensino tradicional, relação da aprendizagem significativa com outras bases teóricas, ensino potencialmente significativo na escola e análise geral da obra.

Revista Educação Online, Rio de Janeiro, n. 30, jan-abr 2019, p. 1-7 
O autor inicia seus escritos situando historicamente 0 behaviorismo, apontando-o como uma perspectiva psicopedagógica influenciada pelos pressupostos da psicologia experimental, vertente que entendia que experiências humanas podiam ser compreendidas através de reações fisiológicas mensuráveis. $A$ psicologia experimental inspirou os trabalhos do psicólogo James B. Watson, que levou postulados desse campo para a área educacional. Watson defendia que o comportamento humano apresenta relação direta com eventos que o precedem (estímulo) e que o sucedem (resposta). A partir disso, apresentou dois princípios para desenvolver a aprendizagem: o princípio da frequência, que apontava a importância de se repetir exercícios para memorizá-los, e o da recentidade, que indicava uma maior eficácia das respostas quanto mais próximas dos estímulos. Apesar de não ter organizado suas ideias em uma teoria consistente, com seus estudos, Watson fundava as bases do behaviorismo.

Todavia, o nome mais conhecido do behaviorismo foi o de B. F. Skinner, que dava ênfase à relação entre resposta e consequência. Skinner trabalhava com os conceitos reforçador positivo e reforçador negativo, sendo o positivo aquele que aumenta a frequência de uma dada resposta, e o negativo aquele que tem 0 comportamento oposto. A partir desses estudos, o enfoque behaviorista foi sendo incorporado à educação, modificando o objetivo central, que, até então, era o de despertar talentos e habilidades inatas, para o processo de expor o estudante a experiências que assegurassem as reações desejadas. Moreira ainda destaca que, apesar de se reconhecer que aprender não é apenas memorizar informações, na realidade escolar, o foco continua sendo a memorização para testes, desenvolvendo o que a literatura internacional conceitua como teaching for testing (ensino para testagem).

Influenciados por esse contexto, o paradigma predominante ainda é o da aprendizagem mecânica com base no behaviorismo, focando o ensino como uma atividade de condicionamento à memorização de informações sem significado para os alunos. A aprendizagem mecânica é desenvolvida com o objetivo de que a nova informação seja internalizada de maneira literal, sem interação cognitiva com conhecimentos prévios, constituindo uma memorização vazia e sem sentido para o aluno.

Revista Educação Online, Rio de Janeiro, n. 30, jan-abr 2019, p. 1-7 
Em contraposição a esse modelo, na década de 1960, o professor e psicólogo educacional David Ausubel começou a desenvolver o que chamou de Teoria da Aprendizagem Significativa, defendendo a ideia de que o ponto inicial para o desenvolvimento da aprendizagem de novos conhecimentos é o que já se conhece. De acordo Ausubel, o processo de aprendizagem se dá através da subsunção, isto é, da interação cognitiva entre os conhecimentos prévios (subsunçores) e os conhecimentos novos, em que os primeiros servem de ancoradouros, pontos de conexão, memorização e compreensão ao novo saber. Os novos conhecimentos são internalizados de maneira substantiva (não ao "pé-da-letra") e não arbitrária, isto é, não interagem de qualquer forma com qualquer conhecimento prévio, mas com algum conhecimento particular, que apresente relações lógicas com o novo saber.

Para a efetivação desse processo, o autor aponta alguns princípios fundamentais, como: a importância da intencionalidade, isto é, aprende-se quando se deseja aprender, a diferenciação progressiva, em que as ideias gerais sobre os temas devem ser apresentadas primeiro, sendo progressivamente detalhadas e especificadas; e a reconciliação integrativa, constante relação desses temas apresentados anteriormente com novos conceitos. Moreira também ressalta a importância dos materiais didáticos, indicando a relevância de que sejam construídos com base na relação entre os subsunçores e os conhecimentos novos.

O autor organiza a TAS em três níveis de aprendizagem significativa: representacional, quando a palavra representa apenas um evento, sem conceitos relacionados, conceitual, que ocorre na medida em que a aprendizagem leva à construção de conceitos que estruturam uma compreensão mais aprofundada sobre determinado evento e proposicional, quando o aluno passa a criar frases complexas com base em vários conceitos. Destacam-se também as formas de desenvolvimento dessa teoria: subordinada, quando ocorre o processo de subsunção, superordenada, quando se percebe a relação do subsunçor com vários conceitos além do conhecimento pretendido e combinatória, na qual a relação construída não é apenas de um subsunçor com um conhecimento novo, e sim com um arcabouço de subsunçores.

Essa estruturação a respeito da TAS fornece ao leitor um repertório teórico que facilita a compreensão de sua aplicabilidade e desenvolvimento durante o 
processo de cognição, bem como para situar as releituras apresentadas por Moreira a partir da contribuição de outros teóricos.

No decorrer da obra, são apresentados alguns enfoques teóricos relacionados com a TAS, igualmente situados no contexto das teorias construtivistas. Um deles é o enfoque humanista de Joseph Novak, que enfatiza o engrandecimento da pessoa como um todo (pensamentos, emoções e intelecto interligados), apontando o ensino potencialmente significativo como um dos meios para se atribuir maior apropriação do conhecimento e, consequentemente, uma relação mais prazerosa entre o aprendiz e os outros quatro elementos do evento educativo (docente, conhecimento, contexto e avaliação).

Outro enfoque teórico é abordado a partir da visão do interacionismo social de David Bob Gowin, que compreende o processo de ensino como uma negociação de significados da tríade professor-aluno-material, através da interação social baseada num diálogo constante. Além disso, o texto apresenta constantes conexões com os trabalhos de Paulo Freire, que, através do seu conceito de dialogicidade, indica a importância de que o educador interaja com os aprendentes para compreender seu contexto de significados, sua cultura e, a partir dela, desenvolva uma educação contextualizada e libertadora. Esse movimento resgata a centralidade do conhecimento prévio para o desenvolvimento de uma aprendizagem que tenha significado para quem aprende.

Nos descritos de Moreira, a dialogicidade apresentada por Freire, somada ao princípio pedagógico do "saber escutar", relaciona-se com a quebra do modelo da narrativa, também criticado pelo pesquisador Donald Finkel, que refuta o modelo tradicional, no qual o professor ensina basicamente falando, apresentando aos estudantes o que eles devem aprender, numa reprodução de coisas dadas e, posteriormente à prova, esquecidas. Assim, Finkel propõe a metáfora dar aulas de boca fechada, levando à reflexão de que devemos repensar o que seria uma boa aula, com um ensino mais voltado a perguntas que ajudem o docente a desenvolver estratégias potencialmente significativas, tornando-o mediador, e não narrador.

Outro aspecto importante a se destacar é a evidenciação das relações teóricas existentes entre a TAS e a teoria dos campos conceituais de Gérard Vergnaud, que estabelece a conceitualização como o núcleo do desenvolvimento cognitivo, em que as situações-problema conferem sentido aos conceitos, e esses, 
para serem aprendidos significativamente, devem fazer sentido para o aprendiz. Há então uma relação entre conceitualização e domínio de um campo conceitual, pois, enquanto vai dominando mais situações, em crescentes níveis de complexidade, mais o sujeito conceitualiza, e quanto mais conceitualiza, mais situações domina.

Desenvolvendo um novo enfoque para a TAS, o autor apresenta a Teoria da Aprendizagem Significativa Crítica (Tasc) como contribuição teórica ao desenvolvimento da teoria de Ausubel. Baseando-se nos postulados da criticidade de Paulo Freire, ele defende que é preciso promover uma aprendizagem que gere curiosidade crítica, subversiva, que fuja de uma aprendizagem mecânica e apassivadora. Ensinar e aprender novos conhecimentos, de forma significativa e crítica, implica em captar seus significados de forma contextualizada e não aceitar passivamente esse conhecimento como verdade absoluta.

Para tanto, Moreira aponta alguns princípios orientadores para a prática docente baseada na Tasc, são eles: princípio da consciência semântica, que lembra ao docente que os significados das palavras precisam ser contextualizados aos significados que os aprendentes compreendem; princípio do conhecimento como linguagem, destacando que a linguagem é fundamental em qualquer processo de tentativa de compreensão da realidade; princípio do aprendiz como preceptor/representador, ressaltando o aprendiz como sujeito que representa as características de seu contexto sociocultural; princípio da diversidade de materiais e estratégias de ensino, com a utilização de várias técnicas e materiais para romper com a monotonia das aulas exclusivamente expositivas e narrativas; princípio da pergunta no lugar da resposta, movimentando a cognição dos alunos, questionando-os e ensinando-os a questionar; princípio da aprendizagem pelo erro, em que esse passa a ser compreendido como parte do processo; princípio da desaprendizagem, que reforça a noção de aprendizagem como um processo contínuo, que, por vezes, passa por desconstruções; princípio da incerteza do conhecimento, que demonstra as mudanças do conhecimento no decorrer do tempo.

Após a fundamentação teórica da TAS e o diálogo com os enfoques e as contribuições de outros autores, Moreira aponta estratégias para a implementação desses pressupostos na sala de aula, objetivando um ensino que supere o comportamentalismo e invista em uma formação humanista dos indivíduos. Nessa

Revista Educação Online, Rio de Janeiro, n. 30, jan-abr 2019, p. 1-7 
direção, ao invés de apenas adotar um livro e segui-lo, o docente precisa realizar um planejamento do que deverá ser ensinado, levando em conta os princípios da diferenciação progressiva, reconciliação integrativa e o mapeamento dos subsunçores.

O primeiro passo é a compreensão de que os conteúdos não são igualmente importantes, haverá sempre aspectos fundamentais e outros mais secundários, o que implica na necessidade de uma criteriosa seleção. Outro aspecto fundamental é a criação de um sistema avaliativo coerente com a TAS, no qual, a partir de uma avaliação diagnóstica, o professor planeje sua matéria de ensino, partindo de conteúdos e estratégias que auxiliem na conexão com os subsunçores dos alunos. Todavia, nem sempre é possível identificar os subsunçores de cada conteúdo. Nesses casos, Ausubel lança mão dos organizadores prévios, conceitos intermediários, analogias direcionadas para a criação de conexão entre os potenciais subsunçores e os novos conhecimentos pretendidos.

Para Moreira, uma mudança significativa na visão e prática de ensino requer também uma mudança no tipo de avaliação, pois não faz sentido, na abordagem construtivista, continuar com a avaliação comportamentalista e dicotômica. Devese então partir para a avaliação formativa, que acompanha em que medida está ocorrendo a aprendizagem, na qual a recursividade permita que $o$ aprendiz refaça as tarefas de aprendizagem, aproveitando o erro como meio para se aprender.

Além de se preocupar com a seleção, organização e avaliação dos conteúdos, o autor atribui grande destaque aos Mapas Conceituais (MC), apontando-os como uma técnica de ensino que pode potencializar o processo de aprendizagem. Os MC são diagramas que apresentam conceitos hierarquizados, iniciando de forma geral com conceitos-chave e avançando gradativamente com o nível de complexidade. São representados simbolicamente por palavras colocadas dentro de caixas, em que a relação entre dois conceitos é representada por uma seta sobre a qual é colocado um verbo ou expressão conectora.

O mapeamento conceitual como estratégia de ensino e aprendizagem é compatível com várias teorias da aprendizagem do campo construtivista, mas, de acordo com o autor, sua idealização se deu com base na TAS, por partir da compreensão que a estrutura cognitiva humana é hierárquica e o aprendizado deve ser regido pelos princípios da diferenciação progressiva e da reconciliação 
integrativa. Esses também são princípios básicos dos $M C$, que, através de sua estruturação, vão levando 0 aprendente a diferenciar progressivamente os conceitos, possibilitando inúmeros movimentos cognitivos de revisão.

Realizando uma análise geral do livro, ressalta-se que o diálogo constante entre a TAS e outras teorias da aprendizagem leva o leitor a uma compreensão mais ampla e estruturada dos avanços da literatura científica nessa respectiva área. A escrita acessível para diversos públicos e a apresentação constante de exemplos práticos torna a obra ainda mais relevante, conferindo ao livro um potencial de aplicabilidade na sala de aula.

Por fim, destaca-se o valor da obra para o campo de ensino-aprendizagem, tanto na pesquisa como na compreensão e utilização da TAS por professores da educação básica e superior. Sua escrita didática sobre as teorias da aprendizagem que vêm influenciando a educação nas últimas décadas, apresentando alguns problemas contemporâneos do ensino, dá à obra esse caráter de complexidade, profundidade e abrangência, colocando-a como uma importante referência na literatura atual da área de ensino-aprendizagem. 